\title{
Produtividade e análise de indicadores técnicos do maracujazeiro-amarelo irrigado em diferentes horários ${ }^{1}$
}

\author{
Haroldo F. de Araújo을 Raimundo N. T. Costa ${ }^{2}$, João R. Crisóstomo ${ }^{3}$, \\ Luís C. U. Saunders ${ }^{2}$, Olavo da C. Moreira ${ }^{2} \&$ Antônia B. M. Macedo ${ }^{2}$
}

\begin{abstract}
RESU M O
Diante da necessidade de pesquisas sobre o manejo da irrigação em horários alternativos e com menor custo com eletricidade na produção do maracujá-amarelo irrigado objetivou-se, com esta pesquisa, avaliar os efeitos do fracionamento da irrigação em diferentes horários de aplicação sobre a produtividade e qualidade do fruto do maracujazeiro-amarelo tal como, também, a quantificação de indicadores técnicos; para tanto se conduziu um experimento no município de Pentecoste, $C E$, no período de setembro de 2009 a agosto de 2010, no delineamento em blocos ao acaso com cinco tratamentos e quatro repetições. $0 \mathrm{~s}$ tratamentos corresponderam aos horários de aplicação da lâmina de água requerida (LR) pela cultura ( $T_{1}: 100 \%$ da LR às $07 \mathrm{~h}$; $T_{2}: 50 \%$ da LR às $07 \mathrm{~h}$ e $50 \%$ da LR às $15 \mathrm{~h} ; \mathrm{T}_{3}: 25 \%$ da LR às $07 \mathrm{~h} ; 50 \%$ da LR às $15 \mathrm{~h}$ e $25 \%$ da LR às $21 \mathrm{~h} 30 \mathrm{~min}$; $\mathrm{T}_{4}: 100 \%$ da LR às $21 \mathrm{~h} 30 \mathrm{~min}$ : $\mathrm{T}_{5}$ : $50 \%$ da LR às $07 \mathrm{~h}$ e $50 \%$ da LR às $21 \mathrm{~h} 30 \mathrm{~min}$ ). De acordo com os resultados a aplicação fracionada da lâmina de água requerida pela cultura com $50 \%$ às $07 \mathrm{~h}$ e $50 \%$ às $21 \mathrm{~h} 30 \mathrm{~min}$, foi a alternativa que proporcionou a maior produtividade do maracujazeiro; os atributos de qualidade dos frutos de maracujazeiro sólidos solúveis totais e $\mathrm{pH}$ se mantiveram indiferentes quanto aos tratamentos.
\end{abstract}

Palavras-chave: Passiflora edulis, lâmina requerida, qualidade de frutos, irrigação noturna

\section{Productivity and technical analysis of indicators of yellow passion fruit irrigated at different times}

\begin{abstract}
Faced with need for the research on management of alternative irrigation schedules and to reduce cost of electricity in production of the irrigated yellow passion fruit, the purpose of this work was to evaluate the effects of fractionation of irrigation at different times on yield and fruit quality of yellow passion fruit, as well as quantification of technical indicators. Therefore, an experiment was carried out in Pentecost, CE northeastern Brazil, from September 2009 to August 2010, in a completely randomized block design with five treatments and four replications. The treatments corresponded to time of application of water depth required (LR) by the crop ( $T_{1}: 100 \%$ of $L R$ at $07 \mathrm{~h}, \mathrm{~T}_{2}: 50 \%$ of $L R$ at $07 \mathrm{~h}$ and $50 \%$ of $L R$ at $15 \mathrm{~h}, \mathrm{~T}_{3}$ : $25 \%$ of LR at $07 \mathrm{~h}, 50 \%$ of LR at $15 \mathrm{~h}$ and $25 \%$ of the LR and $21 \mathrm{~h} 30 \mathrm{~min}, \mathrm{~T}: 100 \%$ of the LR at $21 \mathrm{~h} 30$ min e $T_{5}: 50 \%$ of $L R$ at $07 \mathrm{~h}$ and $50 \%$ of the $L R$ at $21 \mathrm{~h} 30 \mathrm{~min}$ ). Results permitted to conclude following: Application of fractional depth of water required by the crop with $50 \%$ at $07 \mathrm{~h}$ and $50 \%$ at $21 \mathrm{~h} 30 \mathrm{~min}$ was the alternative that provided the highest productivity of passion fruit. The quality attributes of yellow passion fruit with total soluble solids and $\mathrm{pH}$ remained indifferent to the application of water treatments.
\end{abstract}

Key words: Passiflora edulis, blade required, fruit quality, night irrigation

\footnotetext{
${ }^{1}$ Parte da Dissertação de Mestrado do primeiro autor. Trabalho apresentado durante a II Reunião Sulamericana para Manejo e Sustentabilidade da Irrigação em Regiões Áridas e Semiáridas, Cruz das Almas, BA - 03 a 07 de abril de 2011

${ }^{2}$ D EN A/ U FC, Campus do Pici, Bloco 826, CEP 60021-970 Fortaleza, CE. Fone: (85) 3366-9720. E-mail: haroldfa@gmail.com; rntcosta@secrel.com.br; pradmufc@ufc.br; moreira_olavo@yahoo.com.br; brunammacedo@gmail.com

${ }^{3}$ EM BRAPA/CN PAT, Rua D ra. Sara 2270, Planalto Pici, CEP 60511-110. Fortaleza, CE. Fone: (85) 2991916, Ramal: 1916. E-mail: jrcrisost@gmail.com
} 


\section{INTRODUÇÃO}

Nas últimas décadas, a fruticultura irrigada tem obtido espaço na agricultura brasileira de maneira significativa, alcançando grandes avanços no que diz respeito à economia e eficiência de uso de água aplicada pela irrigação, principalmente, na região Nordeste, onde o cultivo se restringe ao uso da irrigação.

O Brasil é o maior produtor mundial de frutas tropicais, com produção de maracujá correspondendo a 719 milhões de toneladas e produtividade média de $13,55 \mathrm{t} \mathrm{ha}^{-1}$ no ano de 2009 (IBGE, 2009). Por se tratar de uma cultura muito rentável financeiramente ao agricultor familiar e garantir fonte de renda bem distribuída o ano todo, a cultura do maracujazeiro irrigado vem se destacando, sobremaneira, na região Nordeste em virtude de oferecer condições edafoclimáticas favoráveis ao bom desenvolvimento da cultura. Atualmente, a região responde por 73,60\% da produção nacional com produtividade média de 11,25 $\mathrm{t} \mathrm{ha}^{-1}$ considerada, portanto, baixa quando comparada com a região sudeste, de 18,40 t ha-1.

De acordo com Cereda \& Vasconcellos (1991) e Araújo Neto et al. (2005) os elementos produtivos do maracujazeiro, número de frutos por planta e peso médio dos frutos, são os grandes responsáveis pelo aumento significativo da produtividade; os demais elementos produtivos, como potencial hidrogeniônico (pH), sólidos solúveis totais ( ${ }^{\circ}$ Brix), rendimento de suco (RS), espessura da casca (EC), comprimento de frutos (CF) e diâmetro de frutos (DF), estão mais relacionados às características desejáveis de mercado da fruta fresca.

Os cultivos com fruticultura no nordeste se restringem ao uso da irrigação, porém o manejo da irrigação feito convencionalmente pelos agricultores da agricultura familiar não vêm apresentando bons resultados técnicos e econômicos, sendo suas principais causas o uso inadequado do manejo da irrigação, que provoca grande desperdício de água pela evaporação devido à deriva e "runoff" e pelo elevado custo com energia elétrica utilizada na irrigação.

Atualmente, há poucas pesquisas em que se utiliza fracionamento da irrigação, combinando horários diurnos e noturnos, principalmente em horário noturno no qual o custo do $\mathrm{kWh}$ de energia chega a ser $73 \%$, conforme a COELCE (2011), mais barato que os horários diurnos. Desta forma e visando suprir a carência de informações sobre o manejo da irrigação em horários alternativos que possibilitam economia com os custos de energia elétrica na irrigação e ainda contribuir para o meio ambiente através do uso eficiente da água aplicada pela irrigação, realizou-se o presente trabalho com o objetivo de valiar os efeitos do fracionamento da irrigação em diferentes horários de aplicação sobre a produtividade e qualidade do fruto do maracujazeiro-amarelo, bem como a quantificação de indicadores técnicos, visando subsidiar os agricultores de informações que os auxiliem no manejo da irrigação para a cultura.

\section{MATERIAL E MÉTODOS}

O experimento foi conduzido no período de setembro de 2009 a agosto de 2010, correspondendo ao primeiro ciclo de produção da cultura em uma área de 24 x $58 \mathrm{~m}$, localizado no Setor C, Lote 07 do Perímetro Irrigado Curu Pentecoste, CE. O tipo climático da região, de acordo com a classificação de Köppen, é BSw'h', pertencente ao grupo de clima semiárido, com precipitação média anual de 797,0 mm concentrada nos meses de janeiro a abril, temperatura média anual máxima de $33,4{ }^{\circ} \mathrm{C}$ e mínima de $22,4{ }^{\circ} \mathrm{C}$ e umidade relativa média do ar de $80 \%$ e demanda evaporativa média de $120 \mathrm{~mm} \mathrm{mês}^{-1}$. A área do experimento apresenta solo Neossolo, com relevo tipicamente plano e classificação textural franco-arenosa; enfim, as caracterizações física e química do solo da camada $0,00 \mathrm{~m}$ a 0,30 m (Tabela 1) foram realizadas no Laboratório de Análises de Solo e Água da UFC.

Os valores dos atributos físicos e químicos demonstram tratar-se de um solo com predominância de areia fina, com baixa quantidade de matéria orgânica e, consequentemente, baixa capacidade de água disponível na área da zona radicular da cultura $(12,82 \mathrm{~mm})$ necessitando-se, desta forma, de uma frequência maior de irrigação, conforme sugerido por (Saeed \& El-Nadi, 1997). O pH se apresenta um pouco fora da faixa ideal para a cultura $(6,0$ a 6,5$)$ porém a saturação por bases está na faixa ideal de $80 \%$, conforme recomenda Borges (2004) para as condições do Nordeste brasileiro.

O preparo do solo consistiu de uma roçagem manual, aração e gradagem. As covas foram abertas no espaçamento de $2,5 \mathrm{~m}$ x 4,0 m, nas dimensões $0,4 \mathrm{~m}$ x $0,4 \mathrm{~m}$ x $0,4 \mathrm{~m}$ recebendo $10 \mathrm{~L}$ de esterco de curral curtido como fonte de matéria orgânica, 0,054 $\mathrm{kg}$ de $\mathrm{P}_{2} \mathrm{O}_{5}$ na forma de superfosfato simples, $0,20 \mathrm{~kg}$ de calcário dolomítico e 0,05 kg de FTE BR 12.

As adubações de formação e de produção, com nitrogênio e potássio, seguiram a recomendação de Borges (2004) para uma produtividade esperada inferior a $15 \mathrm{t} \mathrm{ha}^{-1}$, sendo realizadas por meio de adubação por cobertura. Na fase de formação da cultura (até 120 dias após o transplantio) foram aplicadas quatro adubações na forma de sulfato de amônia para a fonte de nitrogênio e três adubações na forma de cloreto de potássio para a fonte de potássio, a primeira realizada 30 dias após o transplantio somente com N $\left(0,010 \mathrm{~kg} \mathrm{~N} \mathrm{planta}^{-1}\right)$.

Tabela 1. Características físicas e químicas do solo da área da área do experimento

\begin{tabular}{|c|c|c|c|c|c|c|c|c|c|c|c|c|}
\hline \multirow{2}{*}{\multicolumn{2}{|c|}{ Camada (m) }} & \multicolumn{4}{|c|}{ Composição granulométrica (\%) } & & \multirow{2}{*}{\multicolumn{2}{|c|}{ Classe textural }} & \multicolumn{2}{|c|}{ Densidade $\left(\mathrm{kg} \mathrm{m}^{-3}\right)$} & \multirow{2}{*}{ pH } & \multirow{2}{*}{$\begin{array}{c}\text { CE } \\
\text { (dS } \mathrm{m}^{-1} \text { ) }\end{array}$} \\
\hline & & Areia grossa & Areia fina & Silte & Argila & & & & Solo & \multirow{2}{*}{$\begin{array}{c}\text { Partículas } \\
2640\end{array}$} & & \\
\hline 0,00 & 30 & 19 & 60 & 15 & 6 & & Franco arenoso & & 1340 & & 7,1 & 0,19 \\
\hline \multicolumn{9}{|c|}{ Complexo sortivo $\left(\mathrm{cmol}_{\mathrm{c}} \mathrm{kg}^{-1}\right)$} & \multirow{2}{*}{$\begin{array}{c}v \\
(\%)\end{array}$} & \multirow{2}{*}{ PST } & \multirow{2}{*}{$\begin{array}{c}M O \\
\left(g^{~ k g-1}\right)\end{array}$} & \multirow{2}{*}{$\begin{array}{l}\mathbf{P}_{\text {assimilável }} \\
\left(\mathrm{mg} \mathrm{kg}^{-1}\right)\end{array}$} \\
\hline $\mathrm{Ca}^{2+}$ & $\mathrm{Mg}^{2+}$ & $\mathbf{K}^{+}$ & $\mathrm{Na}^{+}$ & \multicolumn{2}{|c|}{$\mathrm{H}^{+}+\mathrm{Al}^{3+}$} & $\mathrm{Al}^{3+}$ & $S$ & $T$ & & & & \\
\hline 4,30 & 2,90 & 0,08 & 0,24 & \multicolumn{2}{|c|}{1,65} & 0 & 7,50 & 9,20 & 82 & 1,00 & 7,76 & 72 \\
\hline
\end{tabular}


Aos 60, 90 e 120 dias após o transplantio foram feitas as outras adubações em cobertura utilizando-se 0,020, 0,030 e $0,040 \mathrm{~kg} \mathrm{~N}_{\text {planta }}{ }^{-1} \mathrm{ano}^{-1}$, respectivamente; também se procedeu, aos 60 dias após o transplantio, à adubação potássica, com 0,010, 0,020 e 0,030 kg de $\mathrm{K}_{2} \mathrm{O}$ planta $^{-1} \mathrm{ano}^{-1}$, de conformidade com a recomendação de Borges (2004) além de análise de solo da área.

O sistema de irrigação utilizado foi o de microaspersão do tipo microjet com dois emissores por planta e vazão de $14 \mathrm{~L} \mathrm{~h}^{-1}$ cada. A fonte hídrica que abasteceu o sistema foi um poço raso tubular situado próximo à área do experimento, cuja água apresentava CE de 1,05 dS m ${ }^{-1}$ e RAS de 2,59, classificada como $\mathrm{C}_{3} \mathrm{~S}_{1}$, ou seja, possui médio risco de salinidade $\left(\mathrm{C}_{3}\right)$ e não oferece risco de sodificação $\left(\mathrm{S}_{1}\right)$.

$\mathrm{O}$ risco de entupimento de gotejadores foi considerado moderado nos aspectos químico e físico, conforme classificação de Nakayama \& Brucks (1986), razão por que não foram analisados os aspectos biológicos.

O delineamento experimental utilizado foi em blocos ao acaso com cinco tratamentos e quatro repetições. Os tratamentos constaram dos horários de aplicação da lâmina de água requerida pela cultura (LR), com frequência de irrigação de dois dias, assim distribuídos: $\mathrm{T}_{1}: 100 \%$ da LR às $07 \mathrm{~h} ; \mathrm{T}_{2}: 50 \%$ da LR às $07 \mathrm{~h}$ e $50 \%$ da LR às $15 \mathrm{~h} ; \mathrm{T}_{3}: 25 \%$ da LR às $07 \mathrm{~h} ; 50 \%$ da LR às $15 \mathrm{~h}$ e $25 \%$ da LR às $21 \mathrm{~h} 30$ min; $\mathrm{T}_{4}: 100 \%$ da LR às $21 \mathrm{~h}$

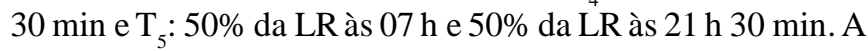
lâmina requerida foi calculada a partir de dados de evaporação de um Tanque Classe A (ECA) instalado próximo à área, associada às condições de instalação e respectivo coeficiente de cultivo da cultura, encontrado por Souza et al. (2009), na mesma região da pesquisa.

Os efeitos dos tratamentos foram analisados com base nas seguintes variáveis: produtividade $\left(\mathrm{kg} \mathrm{ha}^{-1}\right.$ e número de frutos por planta) e indicadores técnicos: peso médio de fruto (PMF), diâmetro de fruto (DF), comprimento de fruto (CF) e espessura da casca (EC) e rendimento de suco (RS). A colheita dos frutos foi iniciada em 24/04/2010 e se estendeu até 20/07/2010 (87 dias), final do $1^{\circ}$ ciclo da cultura. As colheitas ocorriam semanalmente, sendo os frutos colhidos ainda no estádio de pré-climatérico, caracterizado pela mudança na cor verde para amarela, além dos frutos que caíam espontaneamente.

Os dados foram submetidos à análise de variância e à comparação entre as médias, realizada pelo teste de Tukey.

\section{RESULTADOS E DISCUSSÃO}

Na Tabela 2 são apresentados os dados de precipitação pluviométrica e de irrigação durante o período do experimento. Verifica-se que a precipitação pluviométrica contribuiu com $43,25 \%$ do total $956,60 \mathrm{~mm}$, durante o ciclo de cultivo, sendo que $54,10 \%$ dessa contribuição ocorreram somente no mês de abril/10, com $68 \%$ das chuvas distribuídas em apenas quatro dias.

Utilizou-se a estratégia de manejo da irrigação sem déficit, ou seja, aplicação da lâmina de irrigação requerida pela cultura.

A lâmina total de água, considerando-se precipitação e irrigação foi bem próximo do limite inferior da faixa recomendada
Tabela 2. Precipitação pluviométrica (P) e Lâmina de irrigação (L) durante 0 experimento

\begin{tabular}{crrc}
\hline Mês & $\mathbf{P}(\mathbf{m m})$ & $\mathbf{L}(\mathbf{m m})$ & Estágio de desenvolvimento \\
Set/09 & 0,00 & 81,10 & \\
Out/09 & 0,00 & 25,90 & Vegetativo \\
Nov/09 & 0,00 & 50,60 & \\
\hline Dez/09 & 0,00 & 63,60 & \\
Jan/10 & 45,20 & 78,80 & Formação \\
Fev/10 & 20,60 & 90,70 & \\
Mar/10 & 77,60 & 86,30 & \\
\hline Abr/10 & 223,70 & 74,50 & \\
Mai/10 & 32,60 & 106,30 & Floração e produção \\
Jun/10 & 14,00 & 90,20 & \\
Jul/10 & 0,00 & 97,20 & \\
Ago/10 & 0,00 & 111,40 & \\
\hline Total & 413,70 & 956,60 & \\
\hline
\end{tabular}

para a cultura, ou seja, entre 1350 e $1600 \mathrm{~mm}$, conforme Coelho et al. (2000), significando que a demanda hídrica para a cultura foi atendida pelo método utilizado. Freitas (2001) informa que, em condições de sequeiro, o maracujazeiro pode ser cultivado comercialmente em regiões de precipitação anual variável de 800 a $1700 \mathrm{~mm}$, mas as chuvas devem ser bem distribuídas durante o período de emissão de flores e da formação de frutos.

Os resultados das análises de variância contidos na Tabela 3 expressam significância estatística em nível de $1 \%$ de probabilidade para as variáveis produtividade e número de frutos por planta, fato que demonstra que a cultura respondeu de forma diferenciada à sistemática de manejo da irrigação em horários diferenciados, sugerindo uma alternativa na redução de custos com energia elétrica e nas perdas de água por evaporação provocada pela deriva causada pelo vento durante a irrigação diurna. Notadamente, em geral durante a noite a velocidade do vento é menor e, portanto, os desvios de água também; ainda durante o período noturno a umidade relativa do ar é mais alta diminuindo a perda de água e incrementando, assim, a eficiência de uso da água, além de ser uma prática ambientalmente correta.

Tabela 3. Análise de variância para produtividade e número de frutos por planta

\begin{tabular}{lrcc}
\hline \multirow{2}{*}{ Fonte de variação } & \multirow{2}{*}{ GL } & \multicolumn{2}{c}{ Quadrados médios } \\
\cline { 3 - 4 } & & Produtividade & Numero de frutos por planta \\
Blocos & 3 & $6,47 \mathrm{~ns}$ & $55,78 \mathrm{~ns}$ \\
Tratamentos & 4 & $39,54^{* *}$ & $614,17^{* *}$ \\
Resíduos & 12 & 2,29 & 75,74 \\
CV $(\%)$ & & 13,16 & 16,25 \\
\hline ** Significativo em nível de 1\% de probabilidade $(\mathrm{p}<0,01)$ pelo teste $\mathrm{F}$; (ns) não significativo
\end{tabular}

Durante o período diurno, em razão da temperatura mais elevada os sistemas de irrigação desperdiçam muita água e, em consequência, não atingem a eficiência desejada.

De conformidade com o teste de Tukey para comparação de médias (Tabela 4), o tratamento $\mathrm{T}_{5}$, com irrigação fracionada duas vezes ao dia com aplicações de 50\% da lâmina requerida pela manhã e $50 \%$ à noite, demonstrou ser diferente estatisticamente em relação aos demais tratamentos, visto que não apresentaram diferenças estatísticas significativas entre si. 
Tabela 4. Teste de Tukey para comparação de médias

\begin{tabular}{ccc}
\hline Tratamentos & Produtividade & Numero de frutos por planta \\
$\mathrm{T}_{1}$ & $11,67 \mathrm{~b}$ & $53 \mathrm{~b}$ \\
$\mathrm{~T}_{2}$ & $11,30 \mathrm{~b}$ & $55 \mathrm{~b}$ \\
$\mathrm{~T}_{3}$ & $8,95 \mathrm{~b}$ & $46 \mathrm{~b}$ \\
$\mathrm{~T}_{4}$ & $8,97 \mathrm{~b}$ & $42 \mathrm{~b}$ \\
$\mathrm{~T}_{5}$ & $16,66 \mathrm{a}$ & $74 \mathrm{a}$ \\
\hline Médias & 11,51 & 54
\end{tabular}

Médias seguidas da mesma letra não se diferem estatisticamente em nível de $1 \%$ pelo teste de Tukey

Os maiores valores para as duas variáveis estão associados ao tratamento $\mathrm{T}_{5}(50 \%$ LR às $07 \mathrm{~h}$ e $50 \%$ LR às 21 h $30 \mathrm{~min}$ ) em razão, certamente, de um período menor de depleção de água no solo entre duas irrigações consecutivas, se comparados com os dos demais tratamentos. De acordo com trabalhos realizados por Aragão Júnior et al. (1991); Pinto et al. (1994) e Sousa et al. (1999), o manejo de irrigação com maior frequência na aplicação de água condiciona o solo a se manter com ótimo teor de água favorecendo a um desenvolvimento melhor da cultura e, em contrapartida, maior produtividade.

Os valores médios de produtividade da cultura em função dos tratamentos apresentados na Tabela, demonstram que a máxima produtividade $\left(16,66 \mathrm{tha}^{-1}\right)$ obtida no tratamento $\mathrm{T}_{5}$ foi superior $11,8 \%$ à produtividade obtida por Souza et al. (2009), em estudo realizado com a cultura no Perímetro Irrigado Curu Pentecoste, com controle da irrigação por tensiômetro na tensão de $35 \mathrm{kPa}$.

Dentre os tratamentos utilizados (Tabela 4), a variação média de 8,95 t ha-1 a 16,66 t ha-1 para o primeiro ciclo de produção pode estar relacionada à maior disponibilidade hídrica para a cultura visto que os demais fatores que poderiam influenciar a produção permaneceram constantes, em todos os tratamentos.

Vasconcelos (2007) constatou variação de produtividades de $18,47 \mathrm{t} \mathrm{ha}^{-1}$ a 21,57 $\mathrm{t} \mathrm{h}^{-1}$ para combinações de níveis de potássio e níveis de irrigação, nas condições do município de Alvorada do Gurgueia, PI. Costa et al. (2009) observaram em Jataí, GO, avaliando a produção do maracujazeiro-amarelo em condições de sequeiro e irrigado, uma variação de produtividade de 4,20 a 5,30 $\mathrm{tha}^{-1}$ para o primeiro ciclo de produção, que não ocorreu diferença significativa entre os tratamentos e valores bem abaixo dos encontrados nesta pesquisa. Carvalho et al. (2010) observaram, avaliando o desenvolvimento e a produtividade do maracujazeiro-amarelo irrigado sob diferentes lâminas de irrigação em ambiente protegido e natural, produtividade média de 68,24 t ha-1, utilizando alto adensamento das plantas. Esta produtividade verificada pelos autores é uma exceção, visto a produtividade potencial da cultura estar muito aquém da encontrada, conforme verificado por outros pesquisadores outrora citados.

O maior número de frutos por planta foi obtido também no tratamento $\mathrm{T}_{5}$ com 74 frutos por planta, valor próximo ao resultado encontrado por Danatto Junior et al. (2005) que avaliaram adubação orgânica na produção e qualidade de frutos de maracujá-doce. Araújo Neto et al. (2005) obtiveram número de frutos por planta no intervalo de 35,30 a 110,80 para o primeiro ciclo de produção, em estudo com diferentes densidades de plantio. Na Tabela 5 são apresentados os resultados das análises de variância para os indicadores técnicos avaliados do maracujazeiro-amarelo, em função dos tratamentos.

Os resultados demonstraram que das variáveis analisadas apenas o peso médio de frutos se mostrou significativo em nível de $5 \%$ de probabilidade. Os tratamentos $T_{1}, T_{4}$ e $T_{5}$ não diferiram estatisticamente entre si, porém os tratamentos $\mathrm{T}_{2} \mathrm{e}$ $\mathrm{T}_{3}$ diferiram estatisticamente entre si e entre os demais tratamentos (Tabela 6). Esses dois tratamentos apresentam, em comum, horário de irrigação às 15 h, horário de maior demanda evaporativa e deriva de água pelo vento se comparado com os horários dos demais tratamentos; no entanto, as outras variáveis analisadas não apresentaram diferença significativa.

Fazendo uma comparação entre as Tabelas 3 e 5 verifica-se que a produtividade é mais influenciada pelo número de frutos por planta do que pelo peso média dos frutos, corroborando com os resultados observados por Cereda \& Vasconcellos (1991), ao afirmarem que o peso médio de frutos é pouco

Tabela 5. Análise de variância das características físicas e químicas (indicadores técnicos) do maracujazeiro-amarelo

\begin{tabular}{ccccccccc}
\hline \multirow{2}{*}{ Fonte de variação } & \multirow{2}{*}{ GL } & \multicolumn{7}{c}{ Quadrados médios } \\
\cline { 3 - 9 } & & PMF & DF & CF & EC & RS & SST & PH \\
Blocos & 3 & 816,88 & 361,18 & 0,78 & 0,7861 & 14,684 & 3,612 & 0,0109 \\
Tratamentos & 4 & $1741,35^{*}$ & $378,93 \mathrm{~ns}$ & $0,86 \mathrm{~ns}$ & $0,86 \mathrm{~ns}$ & $0,73 \mathrm{~ns}$ & $1,61 \mathrm{~ns}$ & $0,0089 \mathrm{~ns}$ \\
Resíduos & 12 & 332,65 & 372,09 & 1,22 & 1,23 & 32,57 & 1,56 & 0,0085 \\
CV (\%) & & 8,64 & 23,30 & 11,53 & 11,53 & 15,34 & 8,46 & 3,2223 \\
\hline
\end{tabular}

* Significativo em nível de $5 \%$ de probabilidade $(0,01=<p<0,05)$ pelo teste $F$; (ns) não significativo

(PMF) peso médio de fruto; (DF) diâmetro de fruto; (CF) comprimento de fruto; (EC) espessura da casca; (RS) rendimento de suco; (SST) sólidos solúveis totais e (pH) potencial hidrogeniônico

Tabela 6. Comparação de médias pelo teste de Tukey

\begin{tabular}{|c|c|c|c|c|c|c|c|}
\hline \multirow{2}{*}{ Tratamentos } & \multirow{2}{*}{$\begin{array}{c}\text { PMF } \\
\text { (g) }\end{array}$} & DF & CF & EC & RS & SST & \multirow{2}{*}{$\mathrm{pH}$} \\
\hline & & \multicolumn{3}{|c|}{$(\mathrm{mm})$} & \multicolumn{2}{|c|}{$(\%)$} & \\
\hline 1 & $219,71 \mathrm{a}$ & $100,08 \mathrm{a}$ & $89,60 a$ & $9,57 \mathrm{a}$ & $37,3100 \mathrm{a}$ & $14,90 \mathrm{a}$ & $2,80 \mathrm{a}$ \\
\hline 2 & $204,57 a b$ & 78,62 a & $85,12 a$ & $9,90 \mathrm{a}$ & $37,3400 \mathrm{a}$ & $13,68 a$ & $2,83 a$ \\
\hline 3 & $177,38 \mathrm{~b}$ & $77,32 \mathrm{a}$ & $83,59 a$ & $9,75 a$ & $37,2200 \mathrm{a}$ & $14,95 a$ & $2,91 \mathrm{a}$ \\
\hline 4 & $226,27 a$ & 77,82 a & $85,67 \mathrm{a}$ & $9,95 a$ & $37,8700 \mathrm{a}$ & $15,25 a$ & $2,89 a$ \\
\hline 5 & $227,14 a$ & $79,95 \mathrm{a}$ & $89,44 a$ & $8,81 \mathrm{a}$ & $36,6700 \mathrm{a}$ & $15,17 a$ & $2,82 \mathrm{a}$ \\
\hline Médias & 211,01 & 85,34 & 86,70 & 9,60 & 37,2975 & 14,79 & 2,85 \\
\hline
\end{tabular}

Médias com a mesma letra não diferem estatisticamente em nível de $5 \%$ de probabilidade pelo teste de Tukey

(PMF) peso médio de fruto; (DF) diâmetro de fruto; (CF) comprimento de fruto; (EC) espessura da casca; (RS) rendimento de suco; (SST) sólidos solúveis totais; (pH) potencial hidrogeniônico 
influenciado pela maior ou menor produção por planta, e Araújo Neto et al. (2005) que afirmam que a produtividade do maracujazeiro é mais influenciada pelo número de frutos que pelo peso médio dos frutos, fato verificado nesta pesquisa.

De forma geral, o peso médio dos frutos foi superior a $200 \mathrm{~g}$, padrão de classificação da fruta fresca no mercado tipo grande. Carvalho et al. (2000) obtiveram frutos com peso médio entre $147 \mathrm{~g}$ e $161 \mathrm{~g}$, influenciados significativamente pelas diferentes lâminas de irrigação, corroborando com os resultados obtidos nesta pesquisa, uma vez que os tratamentos irrigados fora do horário de maior demanda evaporativa e deriva de água pelo vento, apresentaram os melhores resultados estatisticamente e, teoricamente, por apresentarem uma lâmina maior de água disponível à cultura. Costa et al. (2009) obtiveram 108 g a 115 g, cerca de $100 \%$ de inferioridade em relação aos resultados obtidos nesta pesquisa.

Os valores de diâmetro médio de frutos, comprimento médio de frutos, espessura média da casca e rendimento médio de suco, embora não tenham apresentado diferença significativa em nível de 5\% de probabilidade entre tratamentos, foram bem superiores aos valores obtidos em outros trabalhos, como os desenvolvidos por Borges et al. (2003), Cavichioli et al. (2008) e Costa et al. (2009). Os autores não encontraram efeitos significativos dentre os tratamentos analisados, corroborando com este trabalho.

Danatto Júnior et al. (2005) verificaram, avaliando adubação orgânica na produção de maracujá-doce, uma média de 67,20\% no rendimento de suco, cerca de $44 \%$ superior à verificada nesta pesquisa. Segundo Aular \& Rojas (1994), o rendimento de suco de frutos do maracujazeiro varia de 24 a 60,50\%, sendo influenciado diretamente pela espessura da casca pois, quanto mais espessa a casca menor será o rendimento em suco. As variáveis sólidos solúveis totais e $\mathrm{pH}$ de frutos do maracujazeiro não apresentaram diferenças significativas entre si, a nível de $5 \%$ de probabilidade.

A faixa ideal de sólidos solúveis totais do maracujazeiro se situa entre 13,80 e 18,50\% (Aular \& Rojas, 1994). Este valor é importante uma vez que, para a indústria, os frutos devem apresentar teores elevados de sólidos solúveis totais. $\mathrm{O}$ valor médio de sólidos solúveis totais ( ${ }^{\circ} \mathrm{Brix}$ ) foi de $14,79 \%$, considerado bom para a indústria de suco visto que, segundo Nascimento et al. (2003), para produzir $1 \mathrm{~kg}$ de suco concentrado a $50{ }^{\circ}$ Brix são necessários, para sua industrialização, $11 \mathrm{~kg}$ de frutos com SST, entre $11 \%$ a $12 \%$; em sendo assim, quanto mais alto o valor de SST maior será a quantidade de suco concentrado produzido. Araújo Neto et al. (2005) obtiveram, em estudo com densidade de plantio na cultura do maracujazeiro, Brix de 16,60\%. O valor médio de $\mathrm{pH}$ obtido neste experimento, de 2,85, se encontra na faixa de referência, ou seja, entre 2,70 e 3,10 para a cultura do maracujazeiro (Aular \& Rojas, 1994). Danatto Junior et al. (2005) encontraram pH médio de 3,80 enquanto Costa et al. (2009) verificaram $\mathrm{pH}$ médio de 3,51, porém esses pesquisadores não observaram efeito significativo entre os tratamentos utilizados.

\section{ConClusõEs}

1. A aplicação fracionada da lâmina de água requerida pela cultura com $50 \%$ às 07 h e $50 \%$ às 21 h 30 min, foi o manejo da irrigação que apresentou a maior produtividade e valores para os caracteres de produção número de frutos por planta e peso médio de frutos do maracujazeiro, praticamente o dobro se comparado com os tratamentos que proporcionaram as menores produtividades.

2. Os atributos de qualidade dos frutos de maracujazeiro sólidos solúveis totais e $\mathrm{pH}$, se mantiveram indiferentes quanto aos tratamentos de aplicação de água, fosse a lâmina requerida aplicada em uma único horário ou mesmo fracionada até três vezes ao longo do dia.

\section{Agradecimentos}

Os autores agradecem ao $\mathrm{CNPq} / \mathrm{CT}$-Hidro, pelo financiamento da pesquisa; ao Conselho Nacional de Desenvolvimento Científicoe Tecnológico (CNPq), pela bolsa concedida ao primeiro autor e à Universidade Federal do Ceará (UFC).

\section{LITERATURA CITADA}

Aragão Júnior, T. C.; Magalhães, C. A.; Santos, C. S. V. Efeitos de níveis de umidade no solo em cultivares de melão (Cucumis melo, L.). Fortaleza: EPACE, 1991. 16p. Boletim de Pesquisa, 19

Araújo Neto, S. E. de.; Ramos, J. D.; Andrade Júnior, V. C. de.; Rufini, J. C. M.; Mendonça, V.; Oliveira, T. K. de. Adensamento, desbaste e análise econômica na produção do maracujazeiro-amarelo. Revista Brasileira de Fruticultura, v.27, p.394-398, 2005.

Aular, J.; Rojas, E. Influencia del nitrógeno sobre el crecimiento vegetativo y producción de la parchita (Passiflora edulis Sims f. flavicarpa Degener). Agronomia Tropical, v.44, p.121134, 1994.

Borges, A. L. Nutrição mineral, calagem e adubação. In: Adelise, A. L; Mario, A. P. C. Maracujá: Produção e qualidade na passicultura. 1.ed. Cruz das Almas: EMBRAPA, 2004. cap. 7, p.119-149.

Borges, A. L.; Rodrigues, M. G. V.; Lima, A. de A.; Almeida, I. E. de; Caldas, R. C. Produtividade e qualidade de maracujáamarelo irrigado, adubado com nitrogênio e potássio. Revista Brasileira de Fruticultura, v.25, p.259-262, 2003.

Carvalho, A. J. C. de.; Martins, D. P.; Monnerat, P. H.; Bernardo, S. Adubação nitrogenada e irrigação no maracujazeiro amarelo. Produtividade e qualidade dos frutos. Pesquisa Agropecuária Brasileira, v 35, p.1101-1108, 2000.

Carvalho, J. de A.; Koetz, M.; Sousa, A. M. G. de.; Souza, K. J. de. Desenvolvimento e produtividade do maracujazeiroamarelo irrigado sob diferentes lâminas de irrigação em ambiente protegido e natural. Engenharia Agrícola, v.30, p.862-874, 2010.

Cavichioli, J. C.; Ruggiero, C.; Volpe, C. A. Caracterização físicoquímica de frutos de maracujazeiro-amarelo submetidos à iluminação artificial, irrigação e sombreamento. Revista Brasileira de Fruticultura, v.30, p.649-656, 2008. 
Cereda, E.; Vasconcelos, M. A. S. Influência da densidade de plantio na produtividade do maracujazeiro-amarelo (Passiflora edulis Sims. f. flavicarpa Deg.). Revista Brasileira de Fruticultura, v.13, p.131-135, 1991.

COELCE - Companhia de Eletrificação do Ceará, 2011. < https:/ /www.coelce.com.br/media/60484/tarifas_baixa_tensao _fev_11.pdf> 16 Nov. 2011.

Coelho, E. F.; Sousa, V. F.; Aguiar Netto, A. O.; Oliveira, A. S. Manejo de irrigação em fruteiras tropicais. Cruz das Almas, BA: Embrapa, 2000. 48p. Circular Técnica, 40

Costa, M. M.; Bonomo, R.; Sena Júnior, D. G. de; Gomes Filho, R. R.; Ragagnin, V. A. Produção do maracujazeiro amarelo em condições de sequeiro e irrigado em Jataí - GO. Revista Brasileira de Agricultura Irrigada, v.3, p.13-21, 2009.

Danatto Júnior, E. R.; Leonel, S.; Pedroso, C. J. Adubação orgânica na produção e qualidade de frutos de maracujádoce. Revista Brasileira de Fruticultura, v.27, p.188-190, 2005.

Freitas, G. B. de. Clima e solo. In: Bruckner, C. H.; Picanço, M. C. Maracujá: Tecnologia de produção, pós-colheita, agroindústria, mercado. Porto Alegre: Cinco Continentes, 2001. p.69-83.

IBGE - Instituto Brasileiro de Geografia e Estatística, 2009. <http://www.sidra.ibge.gov.br>03 Jul. 2010.
Nakayama, F. S; Bucks, D. A. Trickle irrigation for crop production: Design, operation and management. Amsterdam: Elsevier, 1986, 164p.

Nascimento, W. M. O. do; Tomé, A. T.; Oliveira, M. do S. P. de; Müller, C. H.; Carvalho, J. E. U. Seleção de progênies de maracujazeiro amarelo (Passiflora edulis $f$. Flavicarpa) quanto à qualidade de frutos. Revista Brasileira de Fruticultura, v.25, p.186-188, 2003.

Pinto, J. M.; Soares, J. M.; Choudhury, E. N.; Choudhury, M. M. Efeitos de períodos e de freqüências da fertirrigação nitrogenada na produção do melão. Pesquisa Agropecuária Brasileira, v.29, p.1345-1350, 1994.

Saeed, I. A. M.; EL-Nadi, A. H. Irrigation effects on the growth, yield and water use efficiency of alfalfa. Irrigation Science, v.17, p.63-68, 1997.

Sousa, V. F. de; Coelho, E. F.; Souza, V. A. B. de. Freqüência de irrigação em meloeiro cultivado em solo arenoso. Pesquisa Agropecuária Brasileira, v.34, p.659-664, 1999.

Souza, M. S. M. de.; Bezerra, F. M. L.; Viana, T. V. A.; Teófilo, E. M.; Cavalcante, I. H. L. Evapotranspiração do maracujá nas condições do vale do Curu. Caatinga, v.22, p.11-16, 2009.

Vasconcelos, D. V. Manejo de água e potássio por fertirrigação no maracujazeiro amarelo em alvorada do Gurguéia, Piauí. Fortaleza: UFC, 2007. 67p. Dissertação Mestrado 